\title{
Indoor smoking policies of Indian tribes in the northwestern United States
}

\author{
Russell E Glasgow, Edward Lichtenstein, Roberta Hall, G Bruce Meyers, \\ Doni Wilder, Suzanne Gilbert McRae
}

\begin{abstract}
Objective - To assess the indoor smoking policies of 39 Indian tribes in the northwestern United States.

Methods-A telephone survey of key tribal leaders conducted in late 1990.

Results-There was substantial variability in smoking policies across tribes and across different settings within the tribes. Sixty-four percent of tribes reported having written smoking policies, the majority of which were implemented in 1989 or later. Tribal schools, council meeting areas, and private offices were most often designated non-smoking, while none of the 15 tribes having bingo halls banned smoking in these areas. Several tribal characteristics were studied, but were not significantly related to stringency of tobacco policy.

Conclusions - There is considerable potential for tobacco policy intervention in Indian tribes. Such policy changes could reduce exposure to environmental tobacco smoke as well as facilitate smoking cessation.

(Tobacco Control 1993; 2: 35-37)
\end{abstract}

\section{Introduction}

While smoking of tobacco in the general US population has been decreasing over the past two decades, ${ }^{1,2}$ it has stayed high among Indian people in the northwest, particularly among women. ${ }^{3}$ Prevalence estimates run at least $50 \%$ higher among Indian people than among the general population in the northwestern US for both smoking and smokeless tobacco use. ${ }^{4,5}$ Some surveys have reported smoking rates of over $50 \% .^{6}$

The major reason to focus on indoor smoking policies for Indian people is the rapidly accumulating evidence on the health consequences of exposure to environmental tobacco smoke (ETS) ${ }^{7,8}$ Although there are no Indianspecific data on the effects of ETS exposure, the high rate of smoking among Native Americans indicates that this is a serious problem. Well-designed tobacco use policies can reduce ETS exposure of both smokers and nonsmokers. Additional reasons for a policy emphasis relate to anticipated long-term effects on tobacco attitudes and use patterns. A comprehensive policy toward tobacco use can enhance participation in smoking cessation programmes, ${ }^{9}$ make it less likely that young persons will take up smoking, ${ }^{10,11}$ and po- tentially result in reduced relapse rates among persons who stop smoking. Establishment of a tribal tobacco policy is culturally appropriate for Native Americans since tribal councils have policy-making authority in their respective settings.

To date, the Indian Health Service has been active in banning smoking in its clinics and in providing support for stopping smoking, ${ }^{12}$ but there has been little or no organised effort to assist tribes in creating and evaluating tobacco use policies. This paper describes the 1990 indoor smoking policies of the 39 federally recognized Indian tribes in the northwestern US and examines tribal characteristics potentially associated with stringency of policy. This information was collected as baseline data for the Tribal Tobacco Project, a randomised trial to develop and evaluate a consultation process to facilitate the development of more comprehensive and effective policies.

\section{Method}

We conducted a standardised 15-20 minute telephone interview with two representatives of each tribe knowledgeable about tribal tobacco policies and health promotion activities. Telephone interviews were employed because the tribes are geographically dispersed over a large, three-state area making face-toface interviews unfeasible. The interview consisted of 15 items covering topics including existing tobacco policy, policy adherence, tribal council characteristics, whether or not tribes received income from tobacco, and smoking cessation services.

Representatives of all 39 tribes participated in interviews. To estimate reliability, a second representative from all but one tribe was interviewed separately. Most often, representatives were tribal health directors $(56 \%)$ or general managers $(28 \%)$. Median percent agreement between informants on items was $82 \%$, with a range of $63 \%-92 \%$. The Spearman rank-order correlation between informants on estimates of tribal size was 0.93 .

\section{CLASSIFICATION OF TOBACCO POLICIES}

Questions were asked about the stringency of smoking policies in seven areas (e.g., council meeting rooms, tribal schools, bingo halls). Within each area, policies were classified as smoke-free, moderately restrictive (e.g., separate or enclosed rooms), or lenient/no policy. To produce a single summary score repre- 
senting tribal smoking policy, scores of 2,1 , and 0 , respectively, were assigned to smokefree, moderately restrictive, and lenient policies within each area and these scores were summed across the three areas that all tribes had in common: council meeting rooms, common work areas, and private work areas.

\section{Results}

As can be seen in table 1 , there is considerable diversity among the 39 tribes on several demographic characteristics. Tribal membership ranges from 130 to 8000 . One-third have a full ambulatory Indian Health Service clinic, and 38 have reservation land. Tribes offered a variety of stop-smoking activities. Of five possible activities inquired about (e.g., stopsmoking classes, smoking assessment as part of health fair, self-help materials, Indian Health Clinic programme, participation in the Great American Smokeout), all but one tribe offered at least one activity and $26 \%$ offered four or more. The mean number of stop-smoking activities was 2.8 (s.d. $=1.2$ ).

All tribes had at least informal policies regarding where members could smoke. Twenty-five tribes $(64 \%)$ reported having written smoking policies, the majority of which $(58 \%)$ were implemented in 1989 or later. As shown in table 2, smoking policies varied considerably across tribes and in different indoor areas. Of the three areas common to all

Table 1 Tribal characteristics

\begin{tabular}{lc}
\hline Tribal characteristic & $\begin{array}{c}\text { Number } \\
\text { of tribes }\end{array}$ \\
\hline Tribal members & \\
$\leqslant 1000$ & 21 \\
$\geqslant 1001$ & 18 \\
Full IHS clinic & 13 \\
Yes & 26 \\
No & 27 \\
Tribal Health Committee & 12 \\
Yes & 25 \\
No & 14 \\
Income from tobacco & \\
Yes & 27 \\
No & 12 \\
Culture area & \\
Coastal & 6 \\
Great Basin or Plateau & 23 \\
Stop-Smoking Activities & 10 \\
$0-1$ & \\
$2-3$ & \\
$4-5$ &
\end{tabular}

tribes, private offices were most likely to be smoke-free areas $(51 \%$ ), while common work areas were least often designated as smoke-free $(23 \%)$, council meeting rooms being intermediate $(44 \%)$. As can be seen in table 2 , tribal areas tended to be either smoke-free or to have lenient or no policies about smoking.

The summary policy scores, which ranged from 0 to 6 (of a possible 6), also revealed this split. Eight tribes were totally smoke-free in all three indoor areas and 10 had lenient policies in all three areas. Policies in other areas were difficult to compare across tribes, since the types of indoor areas varied widely between tribes. Schools were likely to be smoke-free, at least for students. In contrast, none of the 15 tribes that operated bingo halls had even moderate restrictions on smoking in those areas.

Reported adherence to smoking policies was high with $77 \%$ of respondents reporting that smokers in their tribes adhered most or all of the time. If a violation occurred, however, the policy was seldom enforced: only $8 \%$ of the tribes said the policy was always enforced and $31 \%$ said their policy was not enforced at all.

Analyses of possible relationships between tribal characteristics and the summary policy score failed to reveal any significant association.

\section{Discussion}

This is to our knowledge the first populationbased study of the smoking policies of Indian tribes. The strengths of the study include the use of tribes as the unit of analysis, study of several aspects of indoor smoking policies, and the investigation of tribal characteristics potentially related to such policies.

There was considerable variability in the comprehensiveness of smoking policies across tribes. However, none of the tribal characteristics studied were related to tobacco policy scores. In contrast to results from studies of worksite smoking cessation in which larger worksites generally had more stringent smoking policies, ${ }^{13}$ no relationship was found between number of tribal members and policy comprehensiveness.

In Winter 1990-91, smoking was prohibited in most tribal schools and approximately half

Table 2 Stringency of tribal smoking policies by area

\begin{tabular}{|c|c|c|c|}
\hline \multirow[b]{2}{*}{ Tribal area } & \multicolumn{3}{|c|}{ Number of tribes } \\
\hline & $\begin{array}{l}\text { Lenient or } \\
\text { no policy }\end{array}$ & $\begin{array}{l}\text { Moderate } \\
\text { restrictions }\end{array}$ & $\begin{array}{l}\text { Smoke- } \\
\text { free }\end{array}$ \\
\hline \multicolumn{4}{|l|}{ Standard areas: } \\
\hline Council meetings & 13 & 9 & 17 \\
\hline Work: Private offices & 19 & NA & 20 \\
\hline Work: Common areas & 20 & 10 & 9 \\
\hline \multicolumn{4}{|l|}{ Other areas: ${ }^{\star}$} \\
\hline Schools: students & 0 & 1 & 11 \\
\hline $\begin{array}{l}\text { Schools: } \\
\text { teachers/visitors }\end{array}$ & 1 & 6 & 7 \\
\hline Bingo halls & 15 & 0 & 0 \\
\hline Other areas & 5 & 4 & 5 \\
\hline Summary score: & $\begin{array}{c}\text { Mean } \\
2.8\end{array}$ & $\begin{array}{c}\text { Variance } \\
5.4\end{array}$ & $\begin{array}{c}\text { Range } \\
0-6\end{array}$ \\
\hline
\end{tabular}

* These areas were present in only approximately one-third of the tribes. Note that the number varies slightly across areas. $\mathrm{NA}=$ not applicable. 
of the tribal council meetings and private offices studied. This is encouraging, but additional work is needed to protect tribal members better from the deleterious consequences of ETS. There are likely to be high levels of ETS exposure in common work areas, bingo halls, and other recreational areas that do not have policies or have lenient smoking policies $^{14}$.

It is important to emphasise that Indian tribes are separate political entities, not affected by state or federal regulations such as clean indoor air acts. Thus, it is essential to study policy adoption by tribes since they are not subject to the same policy constraints as city and county government. It would be interesting to compare the tobacco policies of these tribes to those of other communities in their vicinity, but such data were not available. It is our impression that tribal smoking policies are similar to the policies in adjacent small communities in the northwestern US.

Efforts are clearly needed to facilitate change in tribal norms for tobacco use. This may be difficult to accomplish in tribes receiving income from tobacco sales, especially those having highly visible smokeshops. Another challenge will be to see if stringent smoking policies can be introduced into bingo halls, which are also large income producers for many tribes.

Our baseline interviews indicate that northwest tribes should be receptive to tobacco policy consultations which assist them to adopt and implement culturally sensitive tobacco policies. Tribes are becoming aware of the dangers of ETS as indicated by the finding that most policies had been adopted in the two years prior to the survey. Reported adherence to smoking policies in tribes that had adopted smoking restrictions was high. In addition, most tribes have smoking cessation activities and alternatives in place that could support attempts to stop smoking by tribal members faced with smoking restrictions.
Future research is needed to: (a) characterise policies on smokeless tobacco use and youth access to tobacco in addition to cigarette smoking policies, and (b) study longitudinally tobacco policies and the relationship of tribal policies to smoking prevalence and tobacco use cessation.

This study was supported by Grant \#UO1 CA52230 from the National Cancer Institute.

1 US Department of Health and Human Services. Reducing the health consequences of smoking. A report of the Surgeon General. Washington, DC: DHHS, 1989. DHHS Publication No (CDC) 88-8406.

2 Warner KE. Smoking and health: A 25-yeår perspective. Am f Public Health 1989; 79: 141-3.

3 Sugarman JR, Warren CW, Oge L, Helgerson SD. Using the Behavioral Risk Factor surveillance system to monitor the Behavioral Risk Factor surveillance system to monitor year 2000

4 Whited DL. Indian specific health plan, report submitted to the Indian Health Service Portland Area Office. Eugene, OR; Southwest Oregon Indian Health Project, 1979.

5 Hall RL, Dexter D. Use of smokeless tobacco among Indian youth in three areas of Washington: Neah Bay, Colville, and Ferndale. Report prepared for the Northwest Portland Indian Health Board; 1988.

6 Hall RL, White D, Bodenroeder P. A survey of knowledge, attitudes and behaviors related to AIDS among Native Americans of Oregon, Idaho, and Washington Native prepared for Northwest Portland Area Indian Health prepared f 1989.

7 National Institute of Occupational Safety and Health. Environmental tobacco smoke in the workplace: Lung cancer Environmental tobacco smoke in the workplace: Lung cancer and other health effects. Current Intelligence Bulletin

8 Glantz SA, Parmley WW. Passive smoking and heart disease: epidemiology, physiology, and biochemistry. Circulation 1991; 83: 1-12.

9 Rigotti NA. Trends in the adoption of smoking restrictions in public places and worksites. NY State 7 Med. Cigarette Smoking Focus on the Workplace. 1989; 89: 19-26.

10 US Department of Health and Human Services. The health consequences of involuntary smoking. A report of the Surgeon General. Washington, DC: 1986. DHHS PubSurgeon General. Washingto
lication No. (CDC) $87-8398$.

11 Pentz MA, Brannon BR, Charlin VI, Barrett EJ, MacKinnon DP, Flay BR. The power of policy: Relationship Kinnon DP, Flay BR. The power of policy: Relationship of smoking policy to adoles

12 Indian Health Service facilities become smoke-free. Morbid Mortal Wkly Rep 1987; 36: 348-50.

13 Glasgow RE, Sorensen G, Corbett $K$. Worksite smoking control activities: Prevalence and related worksite characteristics from the COMMIT study, 1990. Prev Med 1992; $21: 688-700$.

14 Repace J, Lowrey AH. Tobacco smoke, ventilation, and indoor air quality. ASHRAE Trans $1982 ; 88$ : 894-914.

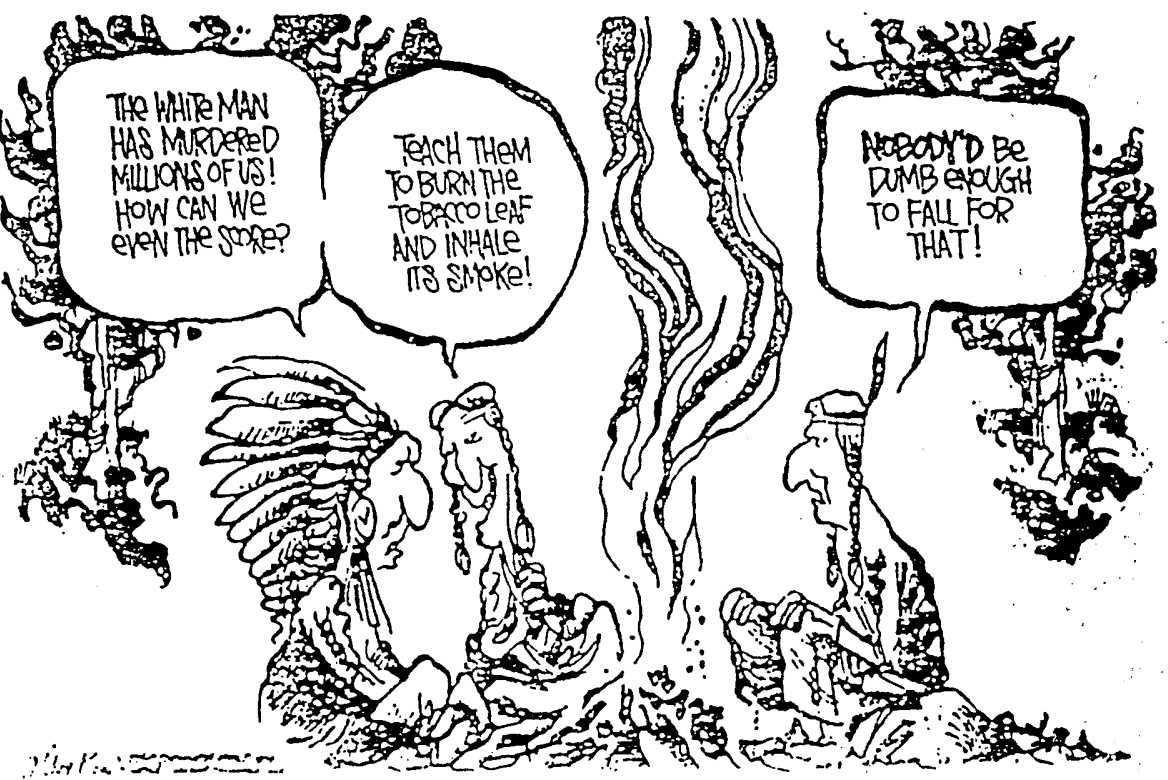

